\title{
Quantifying organ donation rates by donation service area
}

\author{
Akinlolu O. Ojo ${ }^{a}$, , Richard E. Pietroskib, \\ Kevin O'Connor', Joshua J. McGowan ${ }^{\text {d }}$ \\ and David M. Dickinson ${ }^{d}$
}

a Scientific Registry of Transplant Recipients, University of Michigan, Ann Arbor, MI

${ }^{\mathrm{b}}$ Gift of Life Michigan, Ann Arbor, MI

${ }^{\mathrm{c}}$ New England Organ Bank, Newton, MA

d Scientific Registry of Transplant Recipients, University

Renal Research and Education Association, Ann Arbor, MI

*Corresponding author: Akinlolu O. Ojo, aojo@umich.edu

Previous measures of OPO performance based on population counts have been deemed inadequate, and the need for new methods has been widely accepted. This article explains recent developments in OPO performance evaluation methodology, including those developed by the SRTR. As a replacement for the previously established measure of OPO performance donors per million population - using eligible deaths as a national metric has yielded promising results for understanding variations in donation rates among the donation service areas assigned to each OPO. A major improvement uses "notifiable deaths" as a denominator describing a standardized maximal pool of potential donors. Notifiable deaths are defined as in-hospital deaths among ages 70 years and under, excluding certain diagnosis codes related to infections, cancers, etc. A most proximal denominator for determining donation rates is "eligible deaths," which includes only those deaths meeting the criteria for organ donation upon initial assessment. Neither measure is based on the population of a geographic unit, but on restricted upper limits of deaths that could be potential donors in any one locale (e.g., hospital or OPO). The inherent strengths and weaknesses of metrics such as donors per eligible deaths, donors per notifiable deaths, and number of organs per donor are discussed in detail.

Note on sources: The articles in this report are based on the reference tables in the 2004 OPTN/SRTR Annual Report, which are not included in this publication. Many relevant data appear in the figures and tables included here; other tables from the Annual Report that serve as the basis for this article include the following: Tables 1.1, 2.1, 2.2, 2.7, 3.1, 3.4, 3.7, 3.10, 3.13, and 3.16. All of these tables may be found online at http://www.ustransplant.org.

Funding: The Scientific Registry of Transplant Recipients (SRTR) is funded by contract number 231-00-0116 from the Health Resources and Services Administration (HRSA), US Department of Health and Human Services. The views expressed herein are those of the authors and not necessarily those of the US Government. This is a US Government-sponsored work. There are no restrictions on its use.
Key words: organ procurement organizations, donation service areas, organ donation rates, potential donors, notification rates, consent rates, expanded criteria donors, donation after cardiac death, OPO certification, donation referral

\section{Introduction}

New measures of organ procurement rates have been proposed with the intent of identifying regions where fewer than expected organs are being procured. These measures quantify each of several steps in the organ procurement process, and some can be calculated for each hospital, as well as for each organ procurement organization (OPO). Calculation of the rate of deceased donors per million (living) population, a measure that had been used previously, ignores the fact that deceased donors are found at death and that not all deaths have the same likelihood yielding a donor. We explore a wide array of measures under development that will help identify parts of the donation process amenable to improvement by OPOs and the hospitals in their donation service areas (DSAs). None of the measures presented have reached full maturity. However, not only do they represent a step forward in refining assessment, but they also point out where new data sources are needed and which concepts should be incorporated.

Unless otherwise noted, the statistics in this article are drawn from the reference tables in the 2004 OPTN/SRTR Annual Report. Additional statistics are based on OPOspecific reports published by the SRTR. Statistics usually characterize 58 of 59 OPOs, one usually excluded for insufficient data. Two companion articles in this report, 'Transplant data: sources, collection, and research considerations' and 'Analytical approaches for transplant research, 2004 ', explain the methods of data collection, organization and analysis that serve as the basis for this article $(1,2)$. Additional detail on the methods of analysis may be found in the reference tables themselves or in the Technical Notes of the OPTN/SRTR Annual Report, both available online at http://www.ustransplant.org.

\section{Historical context}

\section{The organ procurement organizations (OPOs)}

The OPOs are nonprofit, private agencies responsible for implementing the U.S. organ allocation policies at the local 
level. The OPO is the central functional unit for placement on the waiting list, organ donation and procurement and placement of donated organs. The first OPO was established in 1968 as The New England Organ Bank; its purpose was to serve Massachusetts and neighboring states. Since then, the number of OPOs increased to more than 100 in 1986 but has since decreased to 58. Presently, the OPOs are governed by the National Organ Transplant Act (NOTA) of 1984, as amended, and by directives issued by the Secretary of Health and Human Services through the Centers for Medicare and Medicaid Services (CMS; formerly the Health Care Financing Administration) $(3,4)$. Table 1 outlines requirements for OPOs under NOTA, including the

Table 1: OPO requirements established under NOTA

The OPO must:
Be a non-profit entity
Have a defined service area that is of sufficient size to assure
maximum effectiveness in the procurement and equitable
distribution of organs
Have a director and such other staff, including the organ donation
coordinators and organ procurement specialists, necessary to
effectively obtain organs from donors in its service area
Arrange for appropriate tissue typing of donated organs
Have a system to allocate donated organs equitably among
transplant patients according to established medical criteria
Provide or arrange for the transportation of donated organs to
transplant centers
Participate in the Organ Procurement and Transplantation
Network
Have arrangements to cooperate with tissue banks for the
retrieval, processing, preservation, storage and distribution of
tissues as may be appropriate to assure that all useable
tissues are obtained from potential donors
Evaluate annually the effectiveness of the organization in
acquiring potentially available organs
Assist hospitals in establishing and implementing protocols for
making routine inquiries about organ donations by potential
donors

Sources: $(3,4)$.

Table 2: 1996 Federal register per million population performance standards

\begin{tabular}{cl}
\hline Primary & Actual organ donors per million population* \\
standards & Kidneys recovered per million population* \\
& Kidneys transplanted per million population* \\
& Extra-renal organs recovered per million \\
population* \\
Extra-renal organs transplanted per million \\
population*
\end{tabular}

*Effective from January 1, 1996; each OPO must meet the primary performance standards by achieving at least $75 \%$ of the national mean for 4 of 5 years before the year of redesignation. requirement to meet specific performance objectives (see Table 2) that may be established by CMS (5). The DSA, designated by CMS, is the fundamental geographic unit codified for purposes of organ donation and evaluation. To date, the lack of standard performance measures has made it difficult to precisely evaluate the relative performance of the OPOs. The performance measures described in this manuscript may improve the effort to derive appropriate evaluation tools that can be applied at the various organizational levels involved in the organ donation enterprise, which include OPOs, hospitals and transplant programs.

\section{Designing new procurement measures}

Several attempts have been made to estimate the national organ donor pool and apply methods to measure OPO productivity (6-10). Two different conceptual approaches have emerged for calculating the number of donors that would be expected in a geographic area. Both approaches are useful, and methods to jointly utilize both are described here. One approach attempts to define 'eligible' deaths as those deaths for which a conversion rate of $100 \%$ is at least plausible. Another approach is based on statistical models to estimate the expected number of donors based on the characteristics of the deaths in a region, given the actual experience of the OPOs.

An eligible death is defined as any heartbeating individual meeting, or imminently meeting, the criteria for neurological death (brain death), age 70 years or under, who has not been diagnosed with exclusionary medical conditions published by the Health Resources and Services Administration (HRSA). The conversion rate (also called a donation rate) is the fraction of eligible deaths that become donors; it gives a direct evaluation of those activities most directly attributed to OPO performance. There is general consensus about the definition of an eligible death, although the consistent application of this definition, or its variations, has not yet been well studied. Continued investigation in this area will not only enhance the ability of the government to evaluate the performance of the OPOs, but also and perhaps more importantly, allow OPOs to identify specific areas of operational deficiency that may be corrected through processimprovement activity. Such activities include the Organ Donation Breakthrough Collaborative, which has been initiated by the HRSA Division of Transplantation.

A variety of statistical models have been proposed to estimate the expected number of deceased organ donors within a given DSA, based on the number and characteristics of all of deaths in a region $(6,8,10-12)$. Several investigators have described the potential donor pool using statistical models and hospital medical records. Almost all published approaches rely on the International Classification of Diseases (ICD) codes to identify those deaths most likely to become donor candidates or to identify deceased patients with a diagnostic code consistent with brain 
Akinlolu O. Ojo et al.

Table 3: Historical study variables for potential deceased organ donor measurement

\begin{tabular}{|c|c|c|c|c|c|}
\hline & Christensen et al. & Stogis et al. & Nathan et al. & Sheehy et al. & Ojo et al. \\
\hline \multirow[t]{3}{*}{$\begin{array}{l}\text { Study scope } \\
\text { and period }\end{array}$} & 89 hospitals & $\begin{array}{l}\text { All hospitals in US } \\
\text { and DC }\end{array}$ & $\begin{array}{l}234 \text { hospitals of } \\
\text { Pennsylvania }\end{array}$ & 2239 hospitals & $\begin{array}{l}\text { All hospitals in US and } \\
\text { DC }\end{array}$ \\
\hline & 3 DSAs & All DSAs & 1987 & 36 DSAs & All DSAs \\
\hline & 1993 & 1993-1994 & & 1997-1999 & 1988-1993 \\
\hline $\begin{array}{l}\text { Outcome mea- } \\
\text { surements }\end{array}$ & $\begin{array}{l}\text { Estimate of regional } \\
\text { potential donor } \\
\text { population }\end{array}$ & $\begin{array}{l}\text { Standardized donor } \\
\text { ratio, nationwide } \\
\text { estimate of donor } \\
\text { population }\end{array}$ & $\begin{array}{l}\text { Estimate of state } \\
\text { potential donor } \\
\text { population }\end{array}$ & $\begin{array}{l}\text { Nationwide estimate of } \\
\text { potential donor } \\
\text { population }\end{array}$ & $\begin{array}{l}\text { Crude donation rate, } \\
\text { adjusted donation } \\
\text { rate }\end{array}$ \\
\hline Data source(s) & $\begin{array}{l}\text { Hospital death } \\
\text { record review; } \\
\text { AHA survey } \\
\text { database }\end{array}$ & $\begin{array}{l}\text { NCHS multiple } \\
\text { cause of death } \\
\text { files; UNOS data }\end{array}$ & $\begin{array}{l}\text { Hospital death } \\
\text { record review }\end{array}$ & $\begin{array}{l}\text { Hospital death record } \\
\text { review }\end{array}$ & $\begin{array}{l}\text { NCHS multiple cause } \\
\text { of death files; UNOS } \\
\text { data }\end{array}$ \\
\hline \multirow{3}{*}{$\begin{array}{l}\text { Potential donor } \\
\text { classification } \\
\text { Study character- } \\
\text { istics }\end{array}$} & ICD-9-CM & ICD-9-CM & ICD-9-CM & ICD-9-CM & ICD-9-CM \\
\hline & Exclusion codes & Inclusion codes & Exclusion codes & Exclusion codes & Exclusion codes \\
\hline & $\begin{array}{l}\text { Hospital deaths, } \\
\text { hospital case mix } \\
\text { index, total } \\
\text { hospital beds, } \\
\text { medical school } \\
\text { affiliation, trauma } \\
\text { center } \\
\text { designation, } \\
\text { deaths aged 0-70 } \\
\text { years }\end{array}$ & $\begin{array}{l}\text { Number of } \\
\text { transplant } \\
\text { centers served, } \\
\% \text { population } \\
\text { non-white, } \% \\
\text { population }>50 \\
\text { year, deaths aged } \\
0-75 \text { years }\end{array}$ & $\begin{array}{l}\text { Number of hospital } \\
\text { beds, number of } \\
\text { ICU beds, length } \\
\text { of hospital stay, } \\
\text { trauma center } \\
\text { designation, race, } \\
\text { deaths aged 0-65 } \\
\text { years }\end{array}$ & $\begin{array}{l}\text { Number of hospital beds, } \\
\text { hospital neurosurgical } \\
\text { service, emergency } \\
\text { department, } \\
\text { transplantation center, } \\
\text { deaths aged } 0-70 \\
\text { years }\end{array}$ & $\begin{array}{l}\text { UNOS region, cause of } \\
\text { death, year of death, } \\
\text { sex, race, deaths } \\
\text { aged } 1-65 \text { years }\end{array}$ \\
\hline
\end{tabular}

Sources: $(6,8,10-12)$.

$\mathrm{AHA}=$ American Hospital Association hospital survey database; NCHS = National Center for Health Statistics Cause of Death database; UNOS = United Network for Organ Sharing database.

injury. We call these in-hospital deaths among patients aged 70 years or under without contraindication to donation 'notifiable deaths'; the criteria used to develop and identify this potential donor pool are shown in Table 3. The sources of data for enumerating these deaths include laborintensive physical desk review of individual patient medical records, as well as review of national data obtained from death registries, hospital associations and governmental agencies. In addition to ICD code criteria and upper age limits for deceased patients, other important determinants such as patient demographics and characteristics of health care facilities are considered in developing the estimates of potential donor pools.

Population counts have been rejected as the basis for calculating organ procurement rates in the United States. A 'notifiable' death, defined in terms of age criteria and ICD codes, is one step closer to being a donor, and statistical models can be used to evaluate the potential for donation. An 'eligible' death (also referred to as an eligible donor) is defined as one with an excellent potential for becoming a donor (Table 4). Below, we describe how these concepts can be put together to provide useful assessments for evaluating procurement rates.

\section{Variability in potential organ supply and demand}

Presently, the most accurate prediction of the number of potential donors is derived from the eligible death count.
While the size of the population living in an area is far removed from the expected count of donors, the count of eligible deaths gives a more proximate evaluation of the upper limits of deaths among individuals who could be potential donors, though OPOs often augment this pool with older donors and those who sustain cardiac death (donation after cardiac death or DCD, sometimes called nonheartbeating donors); such donors are not considered 'eligible'. Currently, eligible deaths are self-reported by OPOs and reflect only those deaths referred by hospitals, so the measure is accurate only to the extent that reporting is complete. Since the criteria for defining an eligible death are applied at the bedside by a variety of health care professionals with different levels of experience in organ procurement practices, the reporting is subject to intra- and inter-observer variability. These limitations are being systemically addressed by the OPOs, HRSA, SRTR and OPTN.

\section{Population differences}

Statistical models can be used to study variation in the rate of identification of eligible deaths, just as they were previously used to study the variation in donor procurement rates among all deaths. The resident population for individual DSAs varies widely, from 1.2 million to 17.4 million (U.S. Census data, 2000), and the age distribution and causes of death also vary among DSAs. After accounting for population volume, notifiable deaths account for $6-14 \%$ of all in-hospital deaths across the 58 DSAs. These differences are not amenable to intervention by hospitals or OPOs, but represent underlying differences 
Table 4: Terminology: classifications of donor pool and converted donors

\begin{tabular}{|c|c|c|}
\hline Term & Definition & Examples \\
\hline \multicolumn{3}{|l|}{$\overline{\text { Potential donor pool }}$} \\
\hline Referred deaths & $\begin{array}{l}\text { All deaths or imminent deaths reported by a hospital to the } \\
\text { OPO within the donation service area (DSA). Source: } \\
\text { Many OPOs keep this information, but it is not centrally } \\
\text { collected. }\end{array}$ & 2003 U.S. total $\sim 1.12$ million \\
\hline Notifiable deaths & $\begin{array}{l}\text { In-hospital deaths among patients aged } 70 \text { years or under } \\
\text { whose cause of death was not a contraindication to } \\
\text { donation. Source: Estimated from NCHS data. }\end{array}$ & 2003 U.S. total $\sim 93000$ \\
\hline Eligible deaths (or eligible donors) & $\begin{array}{l}\text { Heartbeating individuals meeting, or imminently meeting, } \\
\text { death by neurological criteria; aged } 70 \text { years or under; who } \\
\text { have not been diagnosed with exclusionary medical } \\
\text { conditions. Source: Reported by OPOs to the OPTN. }\end{array}$ & 2003 U.S. total $\sim 12000$ \\
\hline \multicolumn{3}{|l|}{ Converted donors } \\
\hline Deceased donors & $\begin{array}{l}\text { Individuals from whom at least one organ is recovered with } \\
\text { the intent to transplant. }\end{array}$ & 2003 U.S. total $=6455$ \\
\hline Actual donors (actual vs. eligible) & Deceased donors meeting the criteria of an eligible death. & 2003 U.S. total $=5908$ \\
\hline Additional donors & $\begin{array}{l}\text { Deceased donors who do not meet the criteria of an eligible } \\
\text { death, such as those over } 70 \text { years of age or DCD donors. }\end{array}$ & 2003 U.S. total $=547$ \\
\hline
\end{tabular}

Notes: The definitions of potential donor pools in the top half of the table are placed in order of continually more refined definitions. With perfect reporting and ascertainment, each would be a subset of the previous entries. Terminology about the donation process is evolving, and varies among authors and sources. The terms 'eligible donor', 'actual donor' and 'additional donor' in this table are used by HRSA's Organ Donation Breakthrough Collaborative. NCHS = National Center for Health Statistics Multiple Cause of Death files.

in rates and causes of death among the DSAs. If accurately determined, the projected donors among notifiable deaths gives the most inclusive measure of donation potential in any DSA, since this projection accounts for the rate of identification of eligible deaths by hospitals and for the activities of hospitals and OPOs leading to donation for those eligible deaths. That is, low procurement rates can arise from failure to convert notifiable deaths into eligible deaths and from failure to convert eligible deaths into donors. Both of these processes are reflected in the notification rate.

OPO practices that enumerate and screen all deaths that could potentially become organ donors lead to higher number of eligible deaths. Projections of the expected number of eligible deaths and of the expected number of donors in a region, based on the characteristics of the notifiable deaths in that region, can help to identify those regions where the ascertainment of eligible deaths or donation rates is low.

\section{Mechanism, cause and location of death}

The potential to convert a death to a donor is limited, for the most part, to the causes and mechanisms of death listed in Table 5, with less than $1 \%$ of all in-hospital deaths meeting the cause of death and brain death testing criteria for potential organ donors $(13,14)$. The mechanism and cause of death is another donation determinant that is not amenable to programmatic efforts. The SRTR is currently conducting a retrospective study of the geographic differences in the death rates for the causes of death that are included in the organ donation criteria. More recent trends suggest that financial pressures to reduce prolonged terminal care may reduce the number of deaths occurring in the intensive care unit, where the likelihood of death by neurological criteria (brain death) is higher, thus shifting death toward subacute or even out-of-hospital settings, where potential donor status is much less likely to be established. The rate of deaths occurring in the intensive care units varies widely among DSAs (13) and may contribute to the geographic disparity in deceased donor potential.

Approximately $38 \%$ of all deaths in the United States occur inside an acute care hospital (13), with an even smaller fraction occurring in the controlled environment of the intensive care unit. Since the potential donor whose death occurs outside the hospital is nearly never so identified, differential rates of out-of-hospital deaths may contribute to regional variation in the observed potential donor pool. The extent to which out-of-hospital deaths, through either deescalation of care or other practices, contribute to the geographic differences in potential donor supply is unknown. Based on data obtained from the U.S. Bureau of Census and the National Center for Health Statistics, the rate of inhospital deaths as a percentage of total deaths varies from $28 \%$ to $54 \%$ among the DSAs.

\section{Demand-side factors}

It continues to be reported anecdotally that the presence of high-volume organ transplantation programs and the nature of the relationships among OPOs, procurement surgeons, donor hospitals and transplant centers may have substantial impact on the actual donation rates and lead to differences between DSAs. However, the nine OPOs that are hospital-based have an overall notification rate of 
Table 5: Donor eligibility requirements based on American Academy of Neurology death by neurological criteria

\begin{tabular}{|c|c|}
\hline $\begin{array}{l}\text { Donors aged } 70 \text { years or } \\
\text { younger, excluding*: }\end{array}$ & $\begin{array}{l}\text { Patients under the age of } \\
75 \text { years, including }{ }^{\dagger} \text { : }\end{array}$ \\
\hline Tuberculosis & Malignant neoplasm of the brain \\
\hline $\begin{array}{l}\text { Human immunodeficiency } \\
\text { virus infection with } \\
\text { specified conditions }\end{array}$ & Bacterial meningitis \\
\hline Creutzfeldt-Jacob disease & Intra-cranial abscess \\
\hline Herpetic septicemia & Anoxic brain damage \\
\hline Rabies & Compression of the brain \\
\hline $\begin{array}{l}\text { Reactive hepatitis B surface } \\
\text { antigen }\end{array}$ & Cerebral edema \\
\hline Any retrovirus infection & Other conditions of the brain \\
\hline $\begin{array}{l}\text { Active malignant neoplasm } \\
\text { except primary CNS } \\
\text { tumors and skin cancers }\end{array}$ & Brain death \\
\hline $\begin{array}{l}\text { Hodgkin's disease, multiple } \\
\text { myeloma, leukemia }\end{array}$ & $\begin{array}{l}\text { Unspecified conditions of the } \\
\text { brain }\end{array}$ \\
\hline Miscellaneous carcinomas & Subarachnoid hemorrhage \\
\hline Aplastic anemia & Intra-cerebral hemorrhage \\
\hline Agranulocytosis & $\begin{array}{l}\text { Other/unspecified intra-cerebral } \\
\text { hemorrhage }\end{array}$ \\
\hline Fungal and viral meningitis & $\begin{array}{l}\text { Occlusion and stenosis of } \\
\text { pre-cerebral arteries }\end{array}$ \\
\hline Viral encephalitis & Occlusion of cerebral arteries \\
\hline Gangrene of bowel & Transient cerebral ischemia \\
\hline Extreme immaturity & $\begin{array}{l}\text { Acute, ill-defined cerebrovascular } \\
\text { diagnoses }\end{array}$ \\
\hline \multirow[t]{9}{*}{$\begin{array}{l}\text { Positive serological or viral } \\
\text { culture findings for HIV }\end{array}$} & $\begin{array}{l}\text { Other and ill-defined } \\
\quad \text { cerebrovascular diagnoses }\end{array}$ \\
\hline & $\begin{array}{l}\text { Respiratory arrest } \\
\quad \text { (cardiorespiratory failure) }\end{array}$ \\
\hline & $\begin{array}{l}\text { Intra-cranial injury, excluding } \\
\text { skull fracture }\end{array}$ \\
\hline & Other open wound of the head \\
\hline & Injuries to vessels of head/neck \\
\hline & Traumatic shock \\
\hline & Poisonings \\
\hline & $\begin{array}{l}\text { CNS complications (includes } \\
\text { anoxic brain damage) }\end{array}$ \\
\hline & Cardiopulmonary arrest (CPA) \\
\hline
\end{tabular}

Sources: $(8,12)$.

* Must meet death by neurological criteria as established by the American Academy of Neurology Practices.

${ }^{\dagger}$ Excludes following causes of death: infection; malignancy, except that confined to the primary central nervous system and skin; and renal disease, diabetes mellitus or hypertension with renal insufficiency.

$15 \%$ and a donation rate of $49 \%$, which are just below the 75th and 50th percentile, respectively, among all DSAs. The complex nature of these relationships and the lack of standards upon which to define measurable parameters make it difficult to study and systematically analyze this potentially important variable. An important complicating factor is that potential donors who are likely to yield only non-renal organs may not be aggressively screened and evaluated if there is no transplantation program for the specific non-renal organ in the immediate vicinity of the DSAs. If this practice pattern exists, it may affect a significant mi- nority of the potential donor pool, as donors yielding only non-renal organs account for $11 \%$ of all donors; this likely represents the lower limit of such unidentified and unreported donors. This concern will have limited effect on the measures of donation potential if the reporting of eligible deaths is more uniform and complete.

\section{Currently available measures of donation}

Using multiple measures of DSA performance provides for a more nuanced and complete understanding of where the DSA excels and where opportunities for improvement exist. Since many of these measures take into account underlying variation in organ donor potential (e.g. differential homicide rates and motor-vehicle-related fatality rates), this composite approach to performance measurement is more equitable and constructive than previous approaches based on the local living population or even the simple total number of deaths. As well, using multiple measures of donation allows us to measure not only how successful the members of a DSA are in procuring traditional donors but also how aggressive they may be in seeking additional donors, such as expanded criteria donors, to meet the demands of the ever-growing transplant waiting lists (Table 6).

\section{Donors per notifiable death}

Donors per notifiable death represents an improvement over donors per million as a measure of procurement of traditional donors within a DSA. With the count of notifiable deaths replacing the living population, this measure represents two main advantages over the older measure. First, it measures available deaths rather than population lives; second, it accounts for the viability of a particular death in terms of organ donation. Also, in comparison with a rate that would use eligible deaths as a denominator, it is easily calculable from established counts of inhospital deaths by cause, without needing further chart review or relying on self-reporting by the OPOs of eligible deaths.

This measure reflects the success of a DSA regarding two distinct aspects of the donor procurement process. First, the hospitals within the DSA should efficiently refer every death to the OPO, permitting the OPO the opportunity to evaluate each death for the possibility of donation. Second, the OPO and hospital work together to convert eligible deaths into realized donors. The rate of donors per eligible death is the product of these two processes, as shown in Table 7. By separating these two measures, the user (from OPO to hospital to evaluator) can focus on which segments of the process may be working well and which sections are not.

\section{Notification rates}

Identification and timely notification of potential organ donors to the local OPO have a critical impact on DSA 
Table 6: Measures of DSA performance

\begin{tabular}{|c|c|c|c|c|c|}
\hline \multirow[b]{2}{*}{ Measure: } & \multirow[b]{2}{*}{ Assesses: } & \multicolumn{4}{|c|}{ Range of DSA-specific rates* } \\
\hline & & Min & 25th & 75th & Max \\
\hline Notification rate & $\begin{array}{l}\text { Rate of identification and referral of potential donors within a DSA, } \\
\text { measured by eligible donors referred per notifiable death }\end{array}$ & 6.3 & 10.9 & 14.7 & 23.9 \\
\hline Donation rate & $\begin{array}{l}\text { Rate of recovery of actual donors among eligible deaths identified within a } \\
\text { DSA }\end{array}$ & 30.9 & 42.7 & 56.2 & 84.6 \\
\hline $\begin{array}{l}\text { ECD donors, percentage } \\
\text { of all donors }\end{array}$ & $\begin{array}{l}\text { Aggressiveness in recovering 'non-traditional' donors according to the ECD } \\
\text { kidney definition }\end{array}$ & 5.0 & 15.8 & 23.3 & 43.6 \\
\hline $\begin{array}{l}\text { DCD donors, percentage } \\
\text { of all donors }\end{array}$ & $\begin{array}{l}\text { Aggressiveness in recovering 'non-traditional' donors (any organ) through } \\
\text { utilization of donation after cardiac death }\end{array}$ & 0.0 & 0.0 & 5.7 & 23.5 \\
\hline $\begin{array}{l}\text { Organs recovered per } \\
\text { donor (ORPD) }\end{array}$ & Overall yield of organs in donor recovery process, per recovered donor & 2.7 & 3.4 & 3.7 & $4.3^{*}$ \\
\hline $\begin{array}{l}\text { Organs transplanted per } \\
\text { donor (OTPD) }\end{array}$ & $\begin{array}{l}\text { Overall yield of organs in donor recovery and transplant process, per } \\
\text { recovered donor }\end{array}$ & 2.4 & 3.0 & 3.3 & $3.9^{*}$ \\
\hline
\end{tabular}

Source: Analysis of SRTR OPO-Specific Reports, July 2004; calculated from NCHS Multiple Cause of Death files (for notification rate), referrals reported from the OPO to OPTN (notification rate) and OPTN/SRTR data on donors (all measures).

* Rates shown for ORPD and OTPD reflect all donors; figures for ECD or DCD donors may be lower and therefore OPOs with many ECD and DCD donors may have lower rates.

Table 7: Separation of donor procurement processes

\begin{tabular}{|c|c|c|c|c|}
\hline $\begin{array}{l}\text { Donor yield per } \\
\text { notifiable death }\end{array}$ & & Donation rate & & Notification rate \\
\hline$\frac{\text { Actual donors }}{\text { Notifiable deaths }}$ & $=$ & $\frac{\text { Actual donors }}{\text { Eligible deaths }}$ & $x$ & $\frac{\text { Eligible deaths }}{\text { Notifiable deaths }}$ \\
\hline
\end{tabular}

performance. In a review of 18500 potential organ donors in 36 OPOs from 1997 to 1999, Sheehy et al. noted that the rate of 'missed' referrals was approximately $16 \%$, compared with $27 \%$ in 1990 (10).

Without a full chart review of all deaths at each hospital, such a number is difficult to calculate for each DSA as an ongoing measure. However, national data on in-hospital deaths are available in multiple cause-of-death files from the National Center for Health Statistics (NCHS), allowing us to enumerate notifiable deaths by geographic area or DSA (Table 4). Using this information, a notification rate can be used that measures the following: of the pool of notifiable deaths, what fraction is referred by hospitals to the OPO and identified by the OPO as an eligible death. This version of a notification rate measures the same concept of missed referrals as in the Sheehy study, using a national sample instead of chart review. The chart review in the Sheehy study served to lower the denominator of potential referrals by examining more strict criteria for donor viability, enabling a referral rate in the area of $84 \%(100 \%$ minus $16 \%$ missed referrals). Without such strict criteria available, the larger pool of notifiable deaths within the SRTR method yields notification rates with a much lower average, around 12 per 100 notifiable deaths.

The SRTR provides notification rates in DSA-specific reports. Figure 1 shows that this rate varies from 6.3 to 23.9 , with more than half of the rates for the 58 OPOs falling between 10.9 and 14.7 .

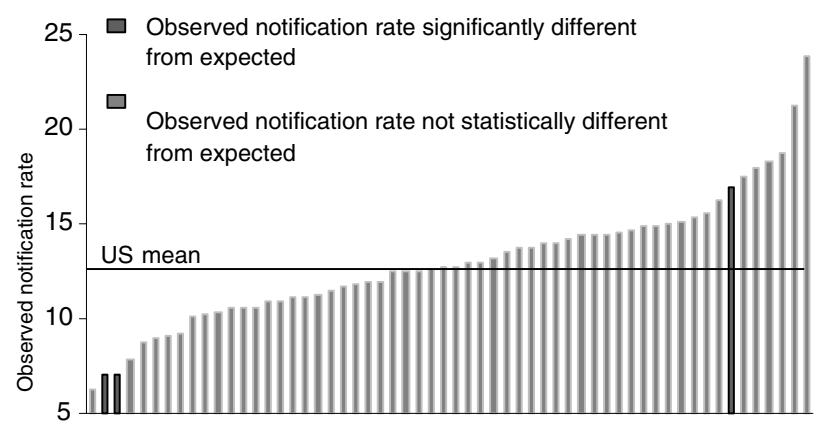

Donation service areas

Figure 1: Observed notification rates reported in DSASpecific Reports, 2003. Source: SRTR analysis, May 2004. One OPO excluded based on insufficient data.

\section{Donation rates}

The donation rate measures the number of actual donors (Table 4) obtained within an OPO per 100 eligible deaths referred by hospitals within that OPO. Along with the notification rate, this statistic is available in the DSA-specific reports produced by the SRTR (Table 6), with an average of about 49 donors converted per 100 eligible deaths (Figure 2). Donation rates vary widely by DSA, from 30.9 to 84.6 .

The separation of the notification rate from the donation rate, as illustrated in Table 7, also allows evaluators to address concerns raised in the transplant and donor procurement community about the reporting of each aspect. The number of donors within each OPO is inherently verified by comparison with the source of organs for actual transplants, but the number of eligible deaths (the denominator of the donation rate) is reported-without verificationby each OPO. Arguably, OPOs with more conservative 


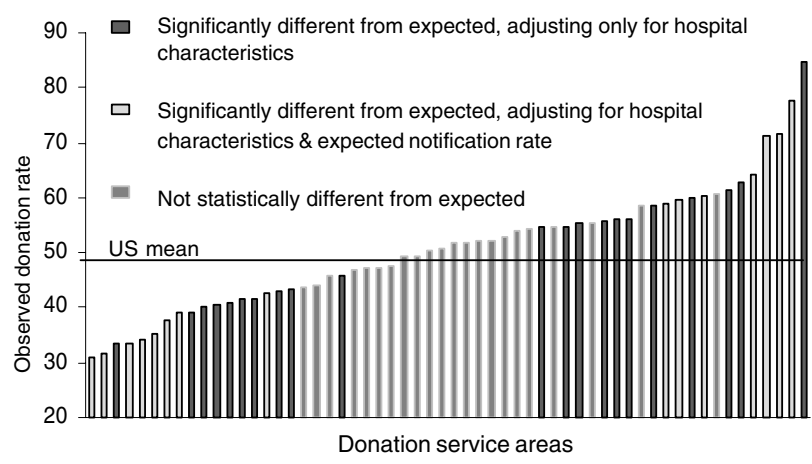

Figure 2: Observed donation rates reported in DSA-Specific Reports, 2003. Source: SRTR analysis, May 2004.

interpretations of the qualifications of an eligible death might yield a smaller denominator here, inflating the donation rate within that DSA. Indeed, when aggregate counts of eligible deaths first began being reported by each OPO for each hospital served, counts for some OPOs yielded implausibly high donation rates, at or above $100 \%$. Since then, community-wide efforts have established a more widely and consistently understood set of definitions. Nevertheless, since the denominator for the donation rate is also the numerator for the notification rate, to the extent that varying interpretations of eligible deaths may persist, the same interpretation that will increase the donation rate of a DSA will decrease its notification rate.

\section{Consent rates}

Consent rates influence DSA performance at two levels. Overall donor consent rates are the key determinant of conversion (donation) rates, and organ-specific consent rates affect the utilization rates of specific organs. The SRTR and OPTN are working together to begin collecting a wider scope of donor data for potential donors referred to OPOs. Such data will include donor consent and enable the identification of differences in consent rates that can be addressed. There also may be underlying population differences in consent rates that affect OPOs differently, such as a tendency to see higher consent rates among younger donors (Sheehy E, AOPO Study, personal communication).

\section{Why adjust?}

The wide variation in both crude notification rates (6-24\%) and crude donation rates (31-85\%) may indicate both the varying success of practices within each DSA, as well as the types of deaths and the conditions under which the hospitals and OPOs operate. Ideally, the characteristics that are out of control of the hospitals and OPOs, such as causes of death of potential organ donors, should be adjusted for while still reflecting their practice patterns.

Currently, the SRTR calculates an 'expected' notification rate for each DSA. A wide range of characteristics of DSAs, their hospitals, and their served populations were tested for associations with higher or lower notification rates. Higher notification rates were found among OPOs whose notifiable deaths are younger, white, female and having high rates of trauma as the cause of death. Using these characteristics to define each OPO, the expected notification rate allows the reader to ask: what notification rate would I expect for this OPO, if it had similar identification of eligible deaths as other OPOs serving similar populations? The expected notification rate, therefore, provides a better comparison point than the national average notification rate, by accounting for differences in these characteristics, which at a national level appear associated with notification of eligible deaths.

Similarly, the expected donation rate is the rate expected based on national experience for OPOs serving similar DSAs and hospitals. Using similar adjustment methodology, it takes into account higher than expected donation from hospitals with characteristics such as level 1 or 2 trauma center, metropolitan statistical area size less than 500000 persons, a high CMS Case Mix Index, a large number of ICU beds (>20), primary service such as a children's hospital and non-government ownership.

Table 8 shows the variation in the expected rates for notification and donation. The third row reflects the expected donation rate, also taking into account the notification rate.

Table 8: Variability in expected notification and donation rates

\begin{tabular}{|c|c|c|c|c|c|}
\hline Rate & Controls for: & Minimum & $\begin{array}{l}\text { 25th } \\
\text { percentile }\end{array}$ & $\begin{array}{l}75^{\text {th }} \\
\text { percentile }\end{array}$ & Maximum \\
\hline $\begin{array}{l}\text { Notification } \\
\quad(\text { expected)* }\end{array}$ & $\begin{array}{l}\text { Distribution of age, sex, race and cause of death among } \\
\text { notifiable deaths within each DSA }\end{array}$ & 9.8 & 11.5 & 13.2 & 18.6 \\
\hline $\begin{array}{l}\text { Donation } \\
\quad(\text { expected })^{\dagger}\end{array}$ & $\begin{array}{l}\text { Level } 1 \text { or } 2 \text { trauma center, metropolitan statistical area size, } \\
\text { CMS Case Mix Index, total bed size, ICU beds, primary } \\
\text { service, and hospital control/ownership }\end{array}$ & 46.6 & 48.7 & 50.2 & 52.9 \\
\hline $\begin{array}{l}\text { Expanded donation } \\
\text { (expected })^{\dagger}\end{array}$ & $\begin{array}{l}\text { Hospital characteristics listed above plus an additional } \\
\text { adjustment of the expected notification rate }\end{array}$ & 41.8 & 47.0 & 52.9 & 60.6 \\
\hline
\end{tabular}

Source: Analysis of SRTR OPO-Specific Reports, July 2004.

* Measured as eligible deaths per 100 notifiable deaths.

${ }^{\dagger}$ Measured as donors per 100 eligible deaths. 
On average, DSAs with higher notification rates have significantly lower donation rates, and this expected donation rate accounts for that difference. The variability among DSAs in these rates shows just how important it is to control for these factors when using rates for performance measures.

The collection and reporting of the characteristics of eligible donors, currently being discussed by the OPTN and SRTR, would allow further adjustment of both conversion rates and of notification rates for those characteristics.

\section{Expanded criteria (kidney) donors (ECD)}

Many OPOs have become more aggressive in seeking out donors who would once have been considered unsuitable, such as expanded criteria donors (ECD), who are older or have a mild history of complications (Table 9). The percentage of recovered donors who qualify as ECD reflects the aggressiveness of an OPO in obtaining these donors. Posttransplant outcomes are worse for ECD donors compared with non-ECD donors. However, for most patients, these organs represent a better option than remaining on the waiting list (15).

The percentage of transplants from ECDs increased to $20 \%$ (1169 donors) of all donors in 2003, compared with $14 \%$ (651 donors) in 1994. During this time when the number of ECD nearly doubled, the number of standard criteria donors (SCDs) increased only 6\%, from 4090 in 1994 to 4329 in 2003.

DSA practices regarding the recovery and transplant of organs from ECDs vary widely. In 2003, the fraction of ECDs (as a percentage of total kidney donors) by DSA ranged from $5 \%$ to $44 \%$ (SRTR analysis, May 2004). There is a clear, inverse relationship between the fraction of donors who are ECD and the rates of organs recovered and transplanted per donor (ORPD/OTPD), since ECDs usually yield fewer organs.

\section{Donation after cardiac death (DCD)}

The percentage of recovered donors who qualify as DCD donors reflects the aggressiveness of an OPO in obtaining these non-traditional donors. There has been a steady growth in DCD transplantation since 1999. Formerly re- ferred to as non-heartbeating donors, DCDs accounted for $4 \%$ of U.S. deceased organ donors in 2003, compared with $1.5 \%$ in $1999,2.0 \%$ in $2000,2.8 \%$ in 2001 and $3.1 \%$ in 2002. The total number of DCD donors has more than tripled in 5 years, from 87 in 1999 to 271 in 2003. In 2003, DCD accounted for $5 \%$ of deceased kidney donors, $3 \%$ of deceased liver donors and $1 \%$ of deceased pancreas donors. There was wide variation among OPOs in the area of DCD in 2003. Twelve OPOs accounted for $79 \%$ of DCDs and 24 OPOs had no DCDs in 2003 (SRTR analysis, May 2004).

\section{Organs per donor}

Two additional measures of DSA performance that persist from the original regulations are the organs recovered per donor (ORPD) and the organs transplanted per donor (OTPD). Inter-OPO variation in DCD and ECD activity has important implications for the number of organs recovered and transplanted per donor at the OPO level.

The mean number of organs transplanted per deceased donor in the United States in 2003 was 3.16 (20 381/6455). For DCD, the mean number of OTPD was 2.04 in 2003. This disparity in OTPD rates for DCD donors (compared with non-DCD donors) results largely from the current limitations on recovery and transplant of thoracic organs from these donors, although DCD did account for $0.3 \%$ of lung donors in 2003. For SCD kidney donors, the mean number of kidneys transplanted was 1.83. For ECD kidney donors (non-DCD), the mean number of kidneys transplanted was 1.24 in 2003. This disparity in OTPD rates between ECD and SCD kidney donors is primarily because of the low rate of organ recovery and transplant from these older donors with comorbidities.

Thus, there are three top-level categories of deceased organ donors: SCD, ECD (defined for kidney allocation but often used to classify donors of any organ) and DCD (nonorgan-specific). The U.S. average rate of OTPD for SCD donors is almost $50 \%$ higher than the rate for ECD, and the average rate of OTPD for non-DCD donors is $55 \%$ higher than for DCD. Furthermore, there is wide variation at the DSA level with respect to recovery and transplant of organs from ECD and DCD donors (Table 6). Some DSAs are very aggressive in their pursuit of both types of

Table 9: Deceased donor classifications

\begin{tabular}{|c|c|c|}
\hline Term & Definition & Example \\
\hline $\begin{array}{l}\text { Expanded criteria } \\
\text { donors (ECD) }\end{array}$ & $\begin{array}{l}\text { For kidney, any deceased donor over the age of } 60 \text { years; or from a } \\
\text { donor over the age of } 50 \text { years with two of the following: a } \\
\text { history of hypertension, a terminal serum creatinine greater than } \\
\text { or equal to } 1.5 \mathrm{mg} / \mathrm{dL} \text { or death resulting from a cerebral vascular } \\
\text { accident (stroke). }\end{array}$ & 2003 U.S. total = 1169 kidney donors \\
\hline $\begin{array}{l}\text { Standard criteria } \\
\text { donors (SCD) }\end{array}$ & $\begin{array}{l}\text { For kidney, a deceased donor who is neither ECD nor DCD. These } \\
\text { donors often have fewer risks associated with donation. }\end{array}$ & 2003 U.S. total $=4329$ kidney donors \\
\hline $\begin{array}{l}\text { Donation after cardiac } \\
\text { death (DCD) }\end{array}$ & $\begin{array}{l}\text { Donation of any organ from patients whose hearts have irreversibly } \\
\text { stopped beating. Includes donors who also qualify as ECD under } \\
\text { the kidney definition above. }\end{array}$ & 2003 U.S. total = 256 kidney donors \\
\hline
\end{tabular}




\section{Akinlolu O. Ojo et al.}

non-standard donors; others are very conservative, and many do not recover any organs from DCDs. In light of this range of practice, it is important to stratify deceased donors for purposes of comparison. Separate analyses of ORPD and OTPD rates by these categories are indicated, since unadjusted rates do not account for the known differences in DSA practices with respect to these three deceased donor categories. In order to avoid providing a disincentive to OPOs for pursuing these non-standard donors, in January 2004 the SRTR began to publish DSA-specific ORPD rates stratified by donor type in its OPO-specific reports.

\section{Summary}

A comprehensive approach to the evaluation of donation potential is a useful tool in the effort to optimize organ donation. Better measures will help identify the practices that yield the best procurement rates. Many of the limitations of historical methods (such as donors per million population) can be overcome by computing multiple measures, including notification rates (eligible deaths per notifiable death), conversion rates (donors per eligible death) and OTPD (organs per donor), with adjustment for the characteristics of the decedents. The proposed measurement tools also have limitations in several respects, including their reliance on self-reported measures of eligible death, lack of uniformity among DSA and hospital staff in applying the definition of eligible deaths and current lack of individual characteristics of eligible deaths. These limitations are surmountable, and efforts are under way among the HRSA, SRTR, OPTN and $A O P O$ to achieve a more uniform implementation of eligible death reporting and more complete and comprehensive data collection that could allow for the urgently needed refinements to the current measurement tools.

\section{References}

1. Dickinson DM, Dykstra DM, Levine GM, Li S, Welch JC, Webb RL. Transplant data: sources, collection, and research considerations, 2004. Am J Transplant 2005; 5(Part 2): 850-861.
2. Schaubel DE, Dykstra DM, Murray S et al. SRTR Report on the state of transplantation: analytical approaches for transplant research, 2004. Am J Transplant 2005; 5(Part 2): 950-957.

3. Organ Procurement Organizations. National organ transplant act. October 19, 1984, Pub L, 100-607.

4. Organ Procurement Organizations. National organ transplant act. Reauthorization. December 21, 2000, 114 Stat, 2763, 2763A29.

5. Medicare and Medicaid programs; conditions of coverage for organ procurement organizations. Fed Regist 1996; 61. May 2, 1996; 19721-19760.

6. Nathan HM, Jarrell BE, Broznik B et al. Estimation and characterization of the potential renal organ donor pool in Pennsylvania. Report of the Pennsylvania Statewide Donor Study. Transplantation 1991; 51: 142-149.

7. Garrison RN, Frederick RB, Raque GH et al. There is an answer to the shortage of organ donors. Gynecol Obstet 1991; 173: 391396.

8. Stogis S, Hirth RA, Strawderman RL, Banaszak-Holl J, Smith DG. Using standardized donor ratio to assess the performance of organ procurement organizations. Health Serv Res 2002; 37: 13291344.

9. Rehnquist J. Office of Inspector General, variation in organ donation among transplant centers. OEI-01-02-00210. May 2003.

10. Sheehy E, Conrad SL, Brigham LE et al. Estimating the number of potential organ donors in the United States. N Engl J Med 2003; 349: 667-674.

11. Christiansen $\mathrm{CL}$, Gormaker SL, Williams JM et al. A method for estimating solid organ donor potential by organ procurement region. Am J Public Heath 1998; 88: 667-674.

12. Ojo AO, Wolfe RA, Leichtman AB, Dickinson DM, Port FK, Young EW. A practical approach to evaluate the potential donor pool and trends in cadaveric kidney donation. Transplantation 1999; 27; 67: 548-556.

13. Opdam HI, Silvester $\mathbf{W}$. Identifying the potential organ donor: an audit of hospital deaths. Intensive Care Med 2004; 30: 13901397.

14. Barnato AE, Mc AE, McClellan MB, Kagay CR, Garber AM. Trends in inpatient treatment intensity among Medicare beneficiaries at the end of life. Health Serv Res 2004; 39: 363-375.

15. Ojo AO, Hanson JA, Meier-Kriesche $\mathrm{H}$ et al. Survival in recipients of marginal cadaveric donor kidneys compared with other recipients and wait-listed transplant candidates. J Am Soc Nephrol 2001; 12: 589-597. 